\title{
Column Adsorption Studies for the Removal of Cr(VI) Ions by Ethylamine Modified Chitosan Carbonized Rice Husk Composite Beads with Modelling and Optimization
}

\author{
S. Sugashini and K. M. Meera Sheriffa Begum \\ Department of Chemical Engineering, National Institute of Technology, Tiruchirappalli 620015, India \\ Correspondence should be addressed to K. M. Meera Sheriffa Begum; meera@nitt.edu
}

Received 26 June 2012; Revised 4 October 2012; Accepted 16 October 2012

Academic Editor: Nurettin Sahiner

Copyright (C) 2013 S. Sugashini and K. M. M. Sheriffa Begum. This is an open access article distributed under the Creative Commons Attribution License, which permits unrestricted use, distribution, and reproduction in any medium, provided the original work is properly cited.

\begin{abstract}
The objective of this present study is the optimization of process parameters in adsorption of $\mathrm{Cr}(\mathrm{VI})$ ions by ethylamine modified chitosan carbonized rice husk composite beads (EAM-CCRCBs) using response surface methodology (RSM) and continuous adsorption studies of $\mathrm{Cr}(\mathrm{VI})$ ions by ethylamine modified chitosan carbonized rice husk composite beads (EAM-CCRCBs). The effect of process variables such as initial metal ion concentration, adsorbent dosage and pH were optimized using RSM in order to ensure high adsorption capacity at low adsorbent dosage and high initial metal ion concentration of $\mathrm{Cr}(\mathrm{VI})$ in batch process. The optimum condition suggested by the model for the process variable such as adsorbent dosage, $\mathrm{pH}$ and initial metal ion concentration was $0.14 \mathrm{~g}, 300 \mathrm{mg} / \mathrm{L}$ and $\mathrm{pH} 2$ with maximum removal of $99.8 \%$ and adsorption capacity of $52.7 \mathrm{mg} / \mathrm{g}$ respectively. Continuous adsorption studies were conducted under optimized initial metal ion concentration and $\mathrm{pH}$ for the removal of $\mathrm{Cr}(\mathrm{VI})$ ions using EAM-CCRCBs. The breakthrough curve analysis was determined using the experimental data obtained from the continuous adsorption. Continuous adsorption modelling such as bed depth service model and Thomson model were established by fitting it with experimental data.
\end{abstract}

\section{Introduction}

Chromium compounds are widely used in various industries such as electroplating, leather tanning, mining, aluminium conversion coating, operation dyes and pigments $[1,2]$. The indiscriminate discharge of chromium metals into water resources causes serious health effect to human and environment because of its toxic nature. Chromium exists in trivalent form and hexavalent form in aqueous systems. Cr(III) ions are non toxic and play an essential role in the metabolism of plant and animals. $\mathrm{Cr}(\mathrm{VI})$ ions are highly toxic. Inhalation of $\mathrm{Cr}(\mathrm{VI})$ ions leads to the carcinogenetic problem. Other health effects of $\mathrm{Cr}(\mathrm{VI})$ ions are the skin allergy liver and stomach problems [3]. The tolerance limit for the discharge of $\mathrm{Cr}(\mathrm{VI})$ ions into surface water is $0.1 \mathrm{mg} / \mathrm{L}$ and in potable water is
$0.05 \mathrm{mg} / \mathrm{L}$ [4]. Thus the removal of $\mathrm{Cr}(\mathrm{VI})$ ions becomes mandatory.

Various methodologies such as electrochemical, ion exchange, membrane filtration, evaporation, solvent extraction, emulsion per traction technology, reverse osmosis and chemical coagulation, and adsorption are available for the removal of $\mathrm{Cr}(\mathrm{VI})$ ions [4].

Adsorption process is one of the efficient methods for $\mathrm{Cr}(\mathrm{VI})$ removal due to its simplicity, sludge-free operation, easiness in handling, availability of various adsorbents, and more efficiently in removal of heavy metals at lowerconcentration levels [5].

Several investigators was used different adsorbents for the removal of $\mathrm{Cr}(\mathrm{VI})$ ions such as activated carbon [6], chitosan [7], biosorbents [8], and polymeric compounds [9]. 
Activated carbon is a common adsorbent because of its high surface area and easy availability, but commercially available activated carbon is highly expensive. Rice husk is one of the cheapest and abundantly available renewable resources in which the constituents of rice husk: cellulose (55-60\%), hemicellulose (20-25\%), and lignin (20-25\%) are used for the preparation of carbon [10-14].

In recent years, activation of carbon with biopolymer to improve the uptake capacity [15-18] has received considerable attention for the removal of transition metal ions and organic species due to its excellent metal chelating property and availability [19-21]. Chitosan, a biopolymer, has great chelating ability of metal ions due to the presence of amino and hydroxyl groups, which also improves the stability in acidic medium by formation of schiff base reaction, and these functional groups can be introduced into chitosan by acylation, etherification, $\mathrm{N}$-alkylation, esterification, or other reactions $[22,23]$.

In recent years, response surface methodology (RSM) has been emphasized, which is a combination of mathematical and statistical techniques used for developing, improving, and optimizing the process variables and to evaluate the relative significance of several process parameters in the presence of complex interactions. The conventional method of optimizing the process variables requires a very large number of experimental runs, which is highly expensive and time consuming. This limitation can be overcome by the statistical experimental design, which reduces the number of experiments and provides appropriate model for process optimization. Response surface methodologies (RSMs) are a useful method to optimize the responses shaped under the influence of process variables [24-27].

Principal RSM is used in experimental design as central composite, box Behnken and Doehlert design. Central composite is a rotatable design requires an experiment number according to $N=2^{n}+2 n+n_{c}$, where $n_{c}$ is the central runs, $N$ is the total number of runs, and $n$ is the number of independent variable.

In our previous study, ethylamine modified chitosan carbonized rice husk composite beads (EAM-CCRCBs) were prepared using rice husk as the precursor for carbonization, and surface modification was done using chitosan. The amino content of the chitosan carbonized rice husk composite beads was increased by ethylamine. Characterizations such as scanning electron microscopy (SEM), Fourier transform infrared spectroscopy (FTIR), and BET analyzer of the adsorbent were also discussed with the prepared (EAM-CCRCBs). The synthesized ethylamine modified chitosan carbonized rice husk composite beads (EAM-CCRCBs) was applied for the removal of hexavalent chromium in batch adsorption process [28].

Thus, this present study intends to investigate the optimization of process variables such as initial metal ion concentration, $\mathrm{pH}$, and adsorbent dosage using central composite design in RSM. Continuous adsorption experiments were conducted under the optimized condition obtained from the RSM. The breakthrough curve was determined from the experiments obtained from continuous process. Continuous adsorption modelling such as bed depth service model and
Thomson model were established by fitting it with experimental data.

\section{Materials and Methods}

2.1. Reagents. Raw rice husk was obtained from a local rice mill. Chitosan was purchased from Pelican Biotech Industry, India. The chemicals used in this study such as nitric acid, sulphuric acid, acetic acid, sodium hydroxide, acetone, ethanol, isopropanol, ethylamine, and epichlorohydrin were supplied by Merck, India. Potassium dichromate was used for the preparation of $\mathrm{Cr}(\mathrm{VI})$ stock solution. The AR grade of 1,5diphenylcarbazide was used for analyzing chromium. Double distilled water was used to prepare all the solutions.

\subsection{Preparation of Ethylamine Modified Chitosan Carbonized} Rice Husk Composite Beads (EAM-CCRCBs). The procedure for preparation and characterization of EAM-CCRCBs was described in our previous study [28]. According to that procedure, the rice husk was thoroughly washed with distilled water and dried in hot air oven at $100^{\circ} \mathrm{C}$ for $5 \mathrm{hrs}$. The dried sample was treated with $70 \%$ concentrated nitric acid (1:1 by weight) at $70^{\circ} \mathrm{C}$ for 90 mins. After acid treatment, the sample was kept for overnight and then subjected to heat under a controlled atmosphere of nitrogen from ambient temperature to $600^{\circ} \mathrm{C}$ at a constant heating rate of $5^{\circ} \mathrm{C} / \mathrm{min}$ in a tubular furnace for $4 \mathrm{hrs}$ [29]. Chitosan gel was prepared by dissolving $3 \mathrm{~g}$ of chitosan in $100 \mathrm{~mL}$ of $2 \%$ acetic acid. $3 \mathrm{~g}$ of carbonized rice husk was added to the chitosan gel and kept in a rotary shaker for $12 \mathrm{hrs}$ at $200 \mathrm{rpm}$. The chitosan carbonized rice husk gel solution was dropped into $0.5 \mathrm{~mol} / \mathrm{L}$ of $\mathrm{NaOH}$ solution which was remained for $12 \mathrm{hrs}$ and washed with distilled water to remove excess $\mathrm{NaOH}$, which is dried for further use.

The prepared CCRCB was introduced into the $60 \mathrm{~mL}$ of isopropanol in a conical flask to obtain a suspension with the CCRCB floating on the surface. A mixture of $5 \mathrm{~mL}$ epichlorohydrin and $100 \mathrm{~mL}$ of water solution of acetone (volume ratio of acetone to water is $1: 1$ ) was added to the suspension and kept in temperature bath at $60^{\circ} \mathrm{C}$ for $2 \mathrm{hrs}$. Then, it was filtered, and the solid beads were transferred into the mixture of $150 \mathrm{~mL}$ of water solution of ethanol (volume ratio of ethanol to water is $1: 1$ ) and $5 \mathrm{~mL}$ of ethylamine, which is kept in temperature bath at $50^{\circ} \mathrm{C}$ for $10 \mathrm{hrs}$. Then, it was washed and dried.

2.3. Adsorption Studies. Batch adsorption studies were conducted to determine the adsorption capacity and percentage removal of $\mathrm{Cr}(\mathrm{VI})$ ions using EAM-CCRCBs. A desired quantity of EAM-CCRCBs was added to $25 \mathrm{~mL}$ of known concentration of $\mathrm{Cr}(\mathrm{VI})$ ions and $\mathrm{pH}$ in a $100 \mathrm{~mL}$ volumetric flask and kept in a rotary shaker at agitation speed of $200 \mathrm{rpm}$. The supernatant liquid samples were separated by centrifuging the sample and then analyzed by using Jasco UV spectrophotometer at $540 \mathrm{~nm}$ to calculate the adsorption capacity and percentage removal. Experiments were repeated in triplicates, and the average percentage deviation was found to be $3-5 \%$. The amount of adsorption at equilibrium 
$q_{e}(\mathrm{mg} / \mathrm{g})$ and percentage removal (\%) were calculated as follows:

$$
\begin{gathered}
q_{e}=\frac{\left(C_{0}-C_{e}\right) V}{m}, \\
\text { Percentage removal }=\left[\frac{\left(C_{0}-C_{t}\right)}{C_{0}}\right] \times 100,
\end{gathered}
$$

where $C_{0}$ and $C_{e}$ are the initial and equilibrium concentrations $(\mathrm{mg} / \mathrm{L}), V$ is the volume of solution $(1), q_{e}$ is the adsorbed quantity $(\mathrm{mg} / \mathrm{g}), \mathrm{m}$ is the weight of adsorbent (g), and $C_{t}$ is the solution concentration at the end of the adsorption process $(\mathrm{mg} / \mathrm{L})$.

2.4. Response Surface Modeling. RSM is a statistical method based on the multivariate nonlinear model that has been widely used for the optimization of process variables of adsorption and also used to determine the regression model equations and operating conditions from the appropriate experiments. It is also useful in studying the interactions of the various parameters affecting the process [30-33].

The standard RSM design called central composite method (CCD) was applied in this present study to determine the optimum process variables for adsorption of $\mathrm{Cr}(\mathrm{VI})$ ions using EAM-CCRCBs by using the design expert software (Version 8.0. Stat-Ease) statistical package. The CCD was used for fitting a quadratic equation by multiple regression procedure which requires only a minimum number of experiments for modelling $[30,31]$. The CCD consists of a $2^{n}$ factorial runs (coded to the usual \pm notation) with $2 n$ axial runs $( \pm \alpha, 0,0, \ldots, 0),(0, \pm \alpha, 0,0, \ldots 0), \ldots,(0,0, \ldots, \pm \alpha)$ and $n_{c}$ center runs (six replicates, $0,0,0, \ldots, 0$ ). The number of factors $n$ increases the number of runs for a complete replicate of the design which is given as folloes:

$$
N=2^{n}+2 n+n_{c}
$$

Basically the optimization process involves three major steps: (1) performing the statistically designed experiments, (2) estimating the coefficients in a mathematical model, and (3) predicting the response and checking the adequacy of the model [32, 33].

An empirical model was developed to correlate the response to the adsorption of $\mathrm{Cr}(\mathrm{VI})$ ions from aqueous solution using EAM-CCRCBs based on second order as folloes:

$$
Y=b_{0}^{\prime}+\sum_{i=1}^{n} b_{i} X_{i}+\sum_{i=1}^{n} b_{i i} X_{i}^{2}+\sum_{i=1}^{n} \sum_{j>1}^{n} b_{i j} X_{i} X_{j},
$$

where $Y$ is the predicted response, $b_{0}^{\prime}$ is the constant coefficient, $b_{i}$ is the linear coefficients, $b_{i j}$ is the interaction coefficients, $b_{i i}$ is the quadratic coefficients, and $X_{i}, X_{j}$ are the coded values.

2.5. Continuous Adsorption Studies. The continuous adsorption studies were conducted in a glass column with internal diameter of $1.5 \mathrm{~cm}$ and length of $40 \mathrm{~cm}$. The EAM-CCRCBs was packed between the glass wool and glass beads in order to prevent the wash out of the adsorbent. A known quantity of adsorbent was then placed in the column to yield the desired bed height $(25 \mathrm{~cm}$ and $15 \mathrm{~cm})$ of the adsorbent. Potassium dichromate solution of known concentration $(300 \mathrm{mg} / \mathrm{L})$ was channelled into the column using a peristaltic pump in upflow manner at the desired flow rate $(25 \mathrm{~mL} / \mathrm{min}$ and $50 \mathrm{~mL} / \mathrm{min}$ ). Samples were collected from the exit of the column at different time intervals and analyzed for $\mathrm{Cr}(\mathrm{VI})$ ions using a UV-Vis Spectrophotometer (JASCO) by monitoring the changes in absorbance at a wavelength of maximum absorbance of $540 \mathrm{~nm}$. Operation of the column was stopped when the effluent $\mathrm{Cr}(\mathrm{VI})$ ion concentration exceeded $99.5 \%$ of its initial concentration.

\section{Results and Discussion}

3.1. Development of Regression Model Analysis. In this present investigation, the CCD of 3 variables such as adsorbent dosage $(\mathrm{g}), \mathrm{pH}$, and initial concentration $(\mathrm{mg} / \mathrm{L})$, each with five levels $( \pm 1$ for the factorial points, 0 for the centre points, and $\pm \alpha$ for the axial points) were chosen as independent variables with designated coded factors as $A, B$, and $C$, respectively, and the variables are presented in Table 1. A total of 20 experiments were necessary to estimate the coefficients of each model using linear regression analysis. The two dependent output responses, namely, percentage removal $\left(Y_{1}\right)$ and adsorption capacity $(\mathrm{mg} / \mathrm{g})\left(Y_{2}\right)$ were obtained from the independent input variables for CCD and are presented in Table 2.

The quadratic models were suggested by the software for percentage removal $\left(Y_{1}\right)$ and adsorption capacity $\left(Y_{2}\right)$ of $\mathrm{Cr}(\mathrm{VI})$ ions removal using EAM-CCRCBs adsorbent due to the higher-order polynomial and are reported in Tables 3 and 4 , respectively.

The quadratic model obtained for the percentage removal $\left(Y_{1}\right)$ and adsorption capacity $\left(Y_{2}\right)$ of $\mathrm{Cr}(\mathrm{VI})$ ions using EAMCCRCBs adsorbent in terms of coded factors was reported as follows:

$$
\begin{aligned}
Y_{1}= & 93.85+11.68 A-5.90 B-6.82 C+1.19 A B \\
& +1.196 A C-0.54 B C-4.71 A^{2}-2.91 B^{2}-2.19 C^{2} \\
Y_{2}= & 54.28-8.42 A-3.73 B+12.59 C+1.73 A B \\
& -0.21 A C+1.06 B C+0.66 A^{2}-1.62 B^{2}-2.55 C^{2}
\end{aligned}
$$

The analysis of variance corresponding to (5) is reported in Tables 5 and 6 . In general, the statistics " $S$ " value with low-probability " $P$ " value represents high significance of the regression model. The model $F$ value of 43.48 and 109.79 implies that the model is significant for percentage removal and adsorption capacity, respectively.

For percentage removal, $A, B, C, A^{2}, B^{2}$, and $C^{2}$ are significant model terms. For adsorption capacity, $A, B, C$, $A B, B^{2}, C^{2}$ are significant model terms. Values greater than 0.1000 indicate that the model terms are not significant. 
TABLE 1: Variables and levels considered for the adsorption of $\mathrm{Cr}(\mathrm{VI})$ using EAM-CCRCBs by CCD.

\begin{tabular}{|c|c|c|c|c|c|c|}
\hline \multirow{2}{*}{ Factors } & & \multicolumn{5}{|c|}{ Range and levels (coded) } \\
\hline & & $-\alpha$ & -1 & 0 & +1 & $+\alpha$ \\
\hline Adsorbent dosage (g) & $A$ & 0.05 & 0.09 & 0.13 & 0.16 & 0.2 \\
\hline $\mathrm{pH}$ & $B$ & 2 & 3 & 4 & 5 & 6 \\
\hline Initial concentration (mg/L) & C & 100 & 200 & 300 & 400 & 500 \\
\hline
\end{tabular}

TABLE 2: Experimental design matrix and responses for the adsorption of $\mathrm{Cr}(\mathrm{VI})$ using EAM-CCRCBs.

\begin{tabular}{|c|c|c|c|c|c|c|c|}
\hline Runs & $A(\mathrm{~g})$ & $B$ & $C(\mathrm{mg} / \mathrm{L})$ & $\begin{array}{c}\text { Actual } \\
Y_{1}\end{array}$ & $\begin{array}{c}\text { Predicted } \\
Y_{1}\end{array}$ & $\begin{array}{c}\text { Actual } \\
Y_{2} \mathrm{mg} / \mathrm{g}\end{array}$ & $\begin{array}{c}\text { Predicted } \\
Y_{2} \mathrm{mg} / \mathrm{g}\end{array}$ \\
\hline 1 & 0.09 & 3 & 200 & 87.1 & 88.40 & 48.40 & 50.78 \\
\hline 2 & 0.16 & 3 & 200 & 99.8 & 104.01 & 31.20 & 30.89 \\
\hline 3 & 0.09 & 5 & 200 & 75.8 & 73.84 & 42.13 & 41.96 \\
\hline 4 & 0.16 & 5 & 200 & 99.4 & 97.10 & 31.09 & 29.01 \\
\hline 5 & 0.09 & 3 & 400 & 69.3 & 71.91 & 77.00 & 78.51 \\
\hline 6 & 0.16 & 3 & 400 & 93.1 & 95.38 & 58.20 & 57.78 \\
\hline 7 & 0.09 & 5 & 400 & 59.1 & 55.20 & 65.70 & 65.45 \\
\hline 8 & 0.16 & 5 & 400 & 87.3 & 86.31 & 54.60 & 51.66 \\
\hline 9 & 0.05 & 4 & 300 & 50.5 & 51.63 & 75.80 & 73.77 \\
\hline 10 & 0.2 & 4 & 300 & 99.8 & 98.36 & 37.50 & 40.10 \\
\hline 11 & 0.13 & 2 & 300 & 99.1 & 94.06 & 57.12 & 55.26 \\
\hline 12 & 0.13 & 6 & 300 & 65.7 & 70.43 & 37.90 & 40.33 \\
\hline 13 & 0.13 & 4 & 100 & 99.2 & 98.73 & 19.10 & 18.90 \\
\hline 14 & 0.13 & 4 & 500 & 71.3 & 71.46 & 68.50 & 69.27 \\
\hline 15 & 0.13 & 4 & 300 & 93.8 & 93.75 & 54.10 & 54.19 \\
\hline 16 & 0.13 & 4 & 300 & 93.8 & 93.75 & 54.10 & 54.19 \\
\hline 17 & 0.13 & 4 & 300 & 93.8 & 93.75 & 54.10 & 54.19 \\
\hline 18 & 0.13 & 4 & 300 & 93.8 & 93.75 & 54.10 & 54.19 \\
\hline 19 & 0.13 & 4 & 300 & 93.8 & 93.75 & 54.10 & 54.19 \\
\hline 20 & 0.13 & 4 & 300 & 93.8 & 93.75 & 54.10 & 54.19 \\
\hline
\end{tabular}

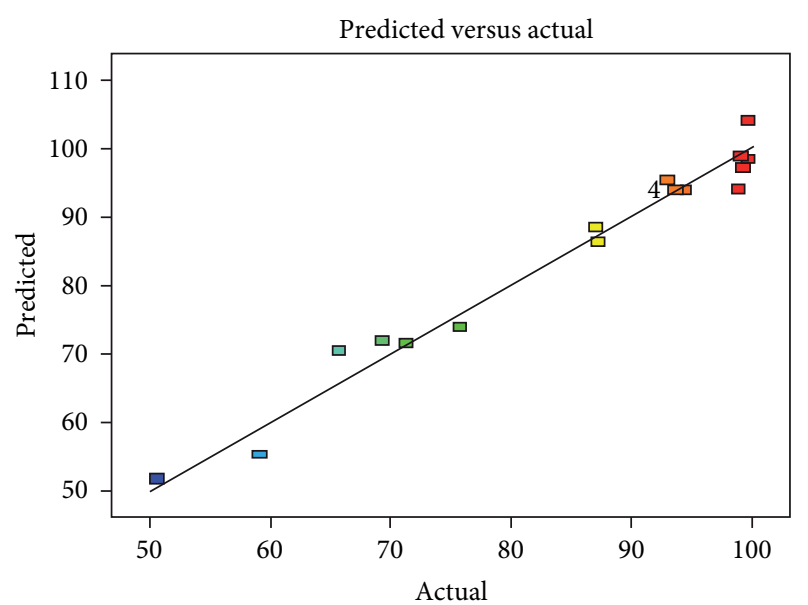

FIGURE 1: The actual and predicted plot for percentage removal of $\mathrm{Cr}(\mathrm{VI})$ ions using EAM-CCRCBs.

Based on (5), the actual and predicted plots for percentage removal and adsorption capacity of $\mathrm{Cr}(\mathrm{VI})$ ions using EAMCCRCBs are shown in Figures 1 and 2. The values of $R^{2}$ and $R_{\text {adj }}^{2}$ were found to be 0.9831 and 0.9679 for percentage

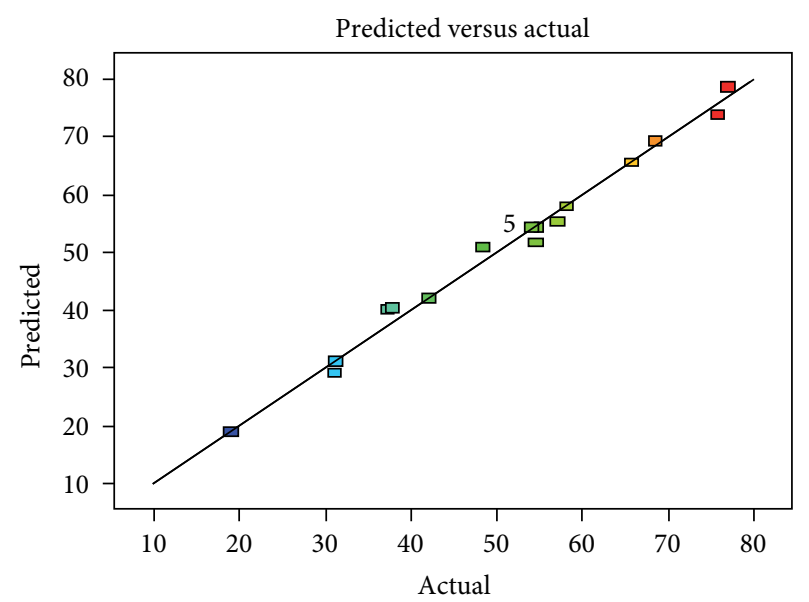

FIgURE 2: The actual and predicted plot for adsorption capacity of $\mathrm{Cr}(\mathrm{VI})$ ions using EAM-CCRCBs.

removal as well as 0.9776 and 0.9574 for adsorption capacity of $\mathrm{Cr}(\mathrm{VI})$ ions using EAM-CCRCBs.

3.2. Interaction Effects of Process Variables. The interaction effects of process variables on percentage removal and 
TABLE 3: Model summary statistics for percentage removal of $\mathrm{Cr}(\mathrm{VI})$ using EAM-CCRCBs.

\begin{tabular}{lcccccc}
\hline Source & Standard deviation & $R^{2}$ & Adj $R^{2}$ & Predicted $R^{2}$ & Press & Comments \\
\hline Linear & 7.26 & 0.8050 & 0.7684 & 0.6944 & 1322.16 & 1671.08 \\
2F1 & 7.75 & 0.8194 & 0.7360 & 0.6138 & 893.29 & Suggested \\
Quadratic & 3.28 & 0.9751 & 0.9527 & 0.7936 & 0.9811 & 8.96 \\
Cubic & 3.7 & 0.9998 & 0.9994 & Aliased \\
\hline
\end{tabular}

TABLE 4: Model summary statistics for adsorption capacity of Cr(VI) using EAM-CCRCBs.

\begin{tabular}{lcccccc}
\hline Source & Standard deviation & $R^{2}$ & $\operatorname{Adj} R^{2}$ & Predicted $R^{2}$ & Press & Comments \\
\hline Linear & 4.49 & 0.9234 & 0.9091 & 0.8578 & 599.71 & 651.27 \\
2F1 & 4.72 & 0.9314 & 0.8997 & 0.8456 & 352.02 & Suggested \\
Quadratic & 2.06 & 0.9900 & 0.9810 & 0.9165 & 228.11 & Aliased \\
Cubic & 0.47 & 0.9997 & 0.9990 & 0.9459 & 221 \\
\hline
\end{tabular}

TABLE 5: Analysis of variance (ANOVA) for response surface quadratic model for percentage removal of Cr(VI) using EAM-CCRCBs.

\begin{tabular}{|c|c|c|c|c|c|c|}
\hline Source & Sum of squares & Df & Mean square & $F$ value & $P$ value & Comments \\
\hline Model & 4219.31 & 9 & 468.81 & 43.48 & $<0.0001$ & Significant \\
\hline$A$ & 2183.23 & 1 & 2183.23 & 202.50 & $<0.0001$ & \\
\hline$B$ & 556.02 & 1 & 556.02 & 51.51 & $<0.0001$ & \\
\hline C & 743.93 & 1 & 743.93 & 69.000 & $<0.0001$ & \\
\hline$A B$ & 29.26 & 1 & 29.26 & 2.71 & 0.1305 & \\
\hline$A C$ & 30.81 & 1 & 30.81 & 2.86 & 0.1218 & \\
\hline$B C$ & 2.31 & 1 & 2.31 & 0.21 & 0.6533 & \\
\hline$A^{2}$ & 558.93 & 1 & 558.93 & 51.84 & $<0.0001$ & \\
\hline$B^{2}$ & 213.44 & 1 & 213.44 & 19.80 & 0.0012 & \\
\hline$C^{2}$ & 120.58 & 1 & 120.58 & 11.18 & 0.0074 & \\
\hline Residual & 107.81 & 10 & 10.78 & & & \\
\hline Lack of fit & 107.37 & 5 & 21.47 & 244.03 & $<0.0001$ & Significant \\
\hline Pure error & 0.44 & 5 & 0.088 & & & \\
\hline Cor total & 4327.12 & 19 & & & & \\
\hline
\end{tabular}

Where $F$ is the fisher value which is the ratio of mean square of the term to the mean square of the residual, and $P$ is low-probability value.

TABLE 6: Analysis of variance (ANOVA) for response surface quadratic model for adsorption capacity of Cr(VI) using EAM-CCRCBs.

\begin{tabular}{|c|c|c|c|c|c|c|}
\hline Source & Sum of squares & Df & Mean square & $F$ value & $P$ value & Comments \\
\hline Model & 4175.38 & 9 & 463.9 & 109.79 & $<0.0001$ & Significant \\
\hline$A$ & 1134.68 & 1 & 1134.68 & 268.52 & $<0.0001$ & \\
\hline$B$ & 222.9 & 1 & 222.9 & 52.75 & $<0.0001$ & \\
\hline$C$ & 2537.14 & 1 & 2537.14 & 600.40 & $<0.0001$ & \\
\hline$A B$ & 24.01 & 1 & 24.01 & 5.68 & 0.0384 & \\
\hline$A C$ & 0.34 & 1 & 0.34 & 0.082 & 0.7811 & \\
\hline$B C$ & 9.07 & 1 & 9.07 & 2.15 & 0.1735 & \\
\hline$A^{2}$ & 11.04 & 1 & 11.04 & 2.61 & 0.1372 & \\
\hline$B^{2}$ & 66.19 & 1 & 66.19 & 15.66 & 0.0027 & \\
\hline$C^{2}$ & 163.49 & 1 & 163.49 & 38.69 & $<0.0001$ & \\
\hline Residual & 42.26 & 10 & 4.23 & & & \\
\hline Lack of fit & 42.05 & 5 & 8.41 & 201.83 & $<0.0001$ & \\
\hline Pure error & 0.21 & 5 & 0.042 & & & \\
\hline Cor total & 4217.64 & 19 & & & & \\
\hline
\end{tabular}




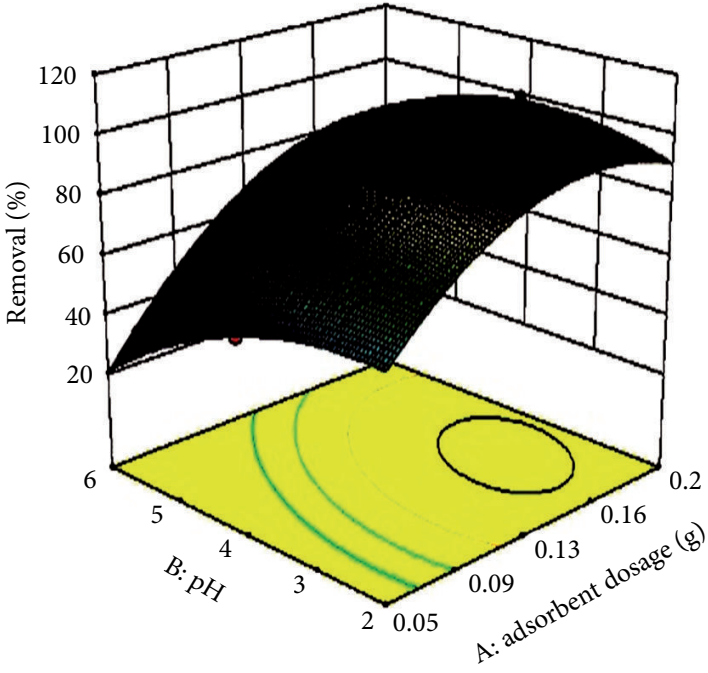

(a)

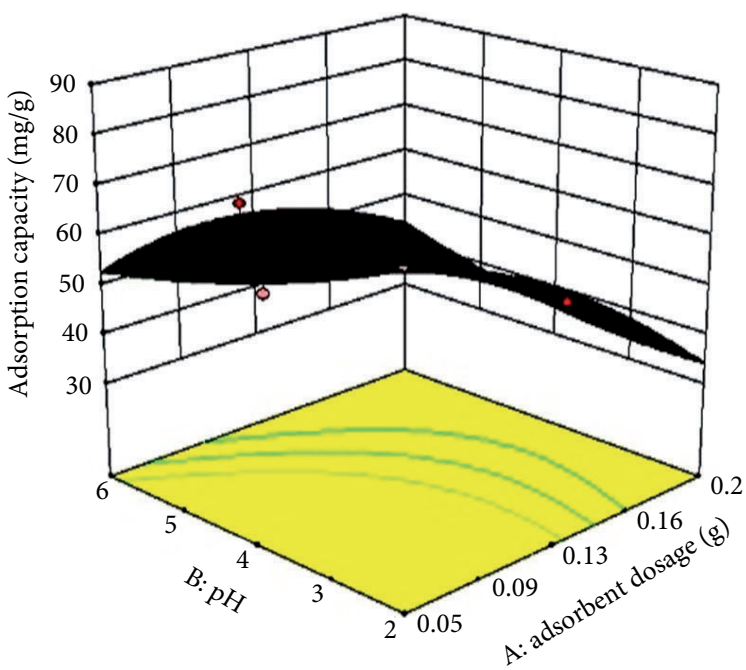

(b)

Figure 3: The combined effect of $\mathrm{pH}$ and adsorbent dosage on (a) percentage removal and (b) adsorption capacity of $\mathrm{Cr}(\mathrm{VI})$ ions using EAM-CCRCBs.

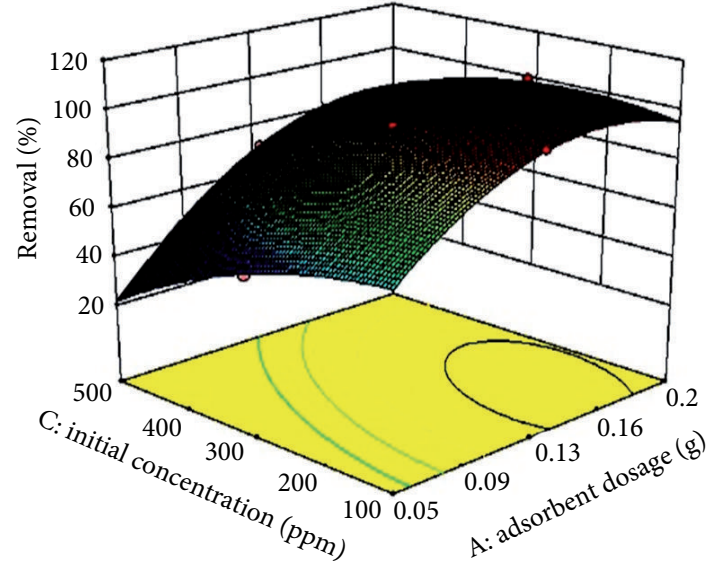

(a)

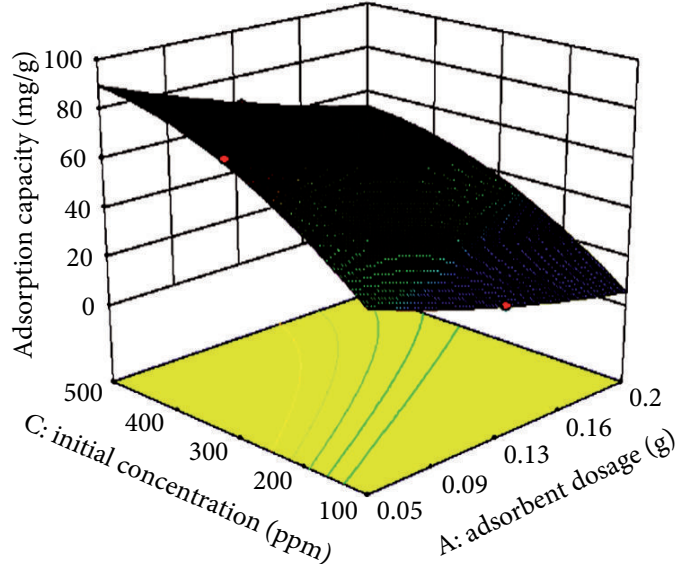

(b)

FIGURE 4: The combined effect of initial concentration and adsorbent dosage on (a) percentage removal and (b) adsorption capacity of Cr(VI) ions using EAM-CCRCBs.

adsorption capacity of $\mathrm{Cr}(\mathrm{VI})$ ions using EAM-CCRCBs were visualized through three-dimensional views of response surface plots and are shown in Figures 3-5.

3.2.1. The Combined Effect of $\mathrm{pH}$ and Adsorbent Dosage. The combined effect of $\mathrm{pH}$ and adsorbent dosage on percentage removal and adsorption capacity of $\mathrm{Cr}(\mathrm{VI})$ ion using EAMCCRCBs is shown in Figures 3(a) and 3(b), respectively. The maximum percentage removal and adsorption capacity of $\mathrm{Cr}(\mathrm{VI})$ ion using EAM-CCRCBs was obtained at $\mathrm{pH} 2$. This may be due to the surface positive functional groups of the EAM-CCRCBs adsorbent carrying the oxyanions (negatively charged) of $\mathrm{Cr}$ (VI) ions by electrostatic force of attraction. At higher $\mathrm{pH}$, the increased negative charges on the adsorbent surface decreased the attraction of oxyanions of $\mathrm{CrO}_{4}{ }^{-2}$ on the adsorbent [34]. The maximum percentage removal of $99.8 \%$ and adsorption capacity of $52.7 \mathrm{mg} / \mathrm{g}$ at constant $\mathrm{pH}$ of 2 initial concentration of $300 \mathrm{mg} / \mathrm{L}$ at EAM-CCRCBs dosage of $0.14 \mathrm{~g}$ was obtained.

3.2.2. The Combined Effect of Initial Metal Ion Concentration and Adsorbent Dosage. Figures 4(a) and 4(b) indicate the combined effect of initial metal ion concentration and adsorbent dosage on percentage removal and adsorption capacity of $\mathrm{Cr}(\mathrm{VI})$ ion using EAM-CCRCBs, respectively. The adsorption capacity was decreased with increased adsorbent dosage, and percentage removal of $\mathrm{Cr}(\mathrm{VI})$ ions was increased with increased adsorbent dosage. The decrease in adsorption capacity might be attributed to the shortage of metal ion concentration in the solution since the initial metal ion 


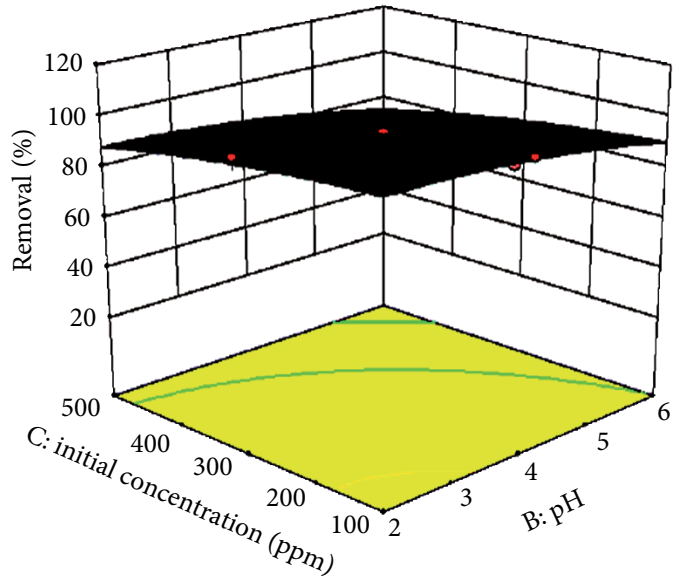

(a)

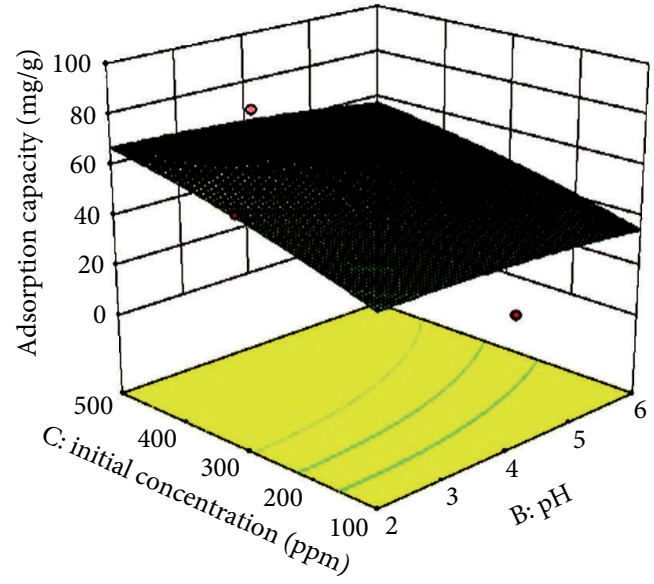

(b)

FIGURE 5: The combined effect of initial concentration and $\mathrm{pH}$ on (a) percentage removal and (b) adsorption capacity of Cr(VI) ions using EAM-CCRCBs.

concentration was kept constant for all varying dosages. The increase in percentage removal may be due to the complete utilization of all active sites in the adsorbent dosage by metal ions [18]. The maximum percentage removal of $92.7 \%$ and adsorption capacity of $58.34 \mathrm{mg} / \mathrm{g}$ at constant $\mathrm{pH}$ of 3.5 and initial concentration of $374.02 \mathrm{mg} / \mathrm{L}$ at $0.14 \mathrm{~g}$ of EAMCCRCBs dosage was obtained.

\subsubsection{The Combined Effect of Initial Metal Ion Concentration} and $p H$. Figures 5(a) and 5(b) represent the combined effect of initial metal ion concentration and $\mathrm{pH}$ on percentage removal and adsorption capacity of $\mathrm{Cr}(\mathrm{VI})$ ion using EAMCCRCBs, respectively. The adsorption capacity of $\mathrm{Cr}(\mathrm{VI})$ ions was increased with increased metal ion concentrations, and the percentage removal of $\mathrm{Cr}(\mathrm{VI})$ ions was decreased with increased metal ion concentrations. This may be due to the availability of active sites is sufficient to occupy the metal ions at lower concentrations. The maximum percentage removal of $92.3 \%$ and adsorption capacity of $63.73 \mathrm{mg} / \mathrm{g}$ at constant $\mathrm{pH}$ of 2 and initial concentration of $374.02 \mathrm{mg} / \mathrm{L}$ at EAM-CCRCBs dosage of $0.13 \mathrm{~g}$ was obtained.

3.3. Optimization by RSM. In order to achieve the maximum adsorption of $\mathrm{Cr}(\mathrm{VI})$ ions using EAM-CCRCBs, the optimum process variables were found from the developed mathematical model. The optimum condition suggested by the model for the process variable such as adsorbent dosage, and initial metal ion concentration was $0.14 \mathrm{~g}$, and $300 \mathrm{mg} / \mathrm{L}$ at $\mathrm{pH} 2$ with maximum removal of $99.8 \%$ and adsorption capacity of $52.7 \mathrm{mg} / \mathrm{g}$, respectively, and is shown in Table 7.

3.4. Continuous Adsorption Studies. The performance of a fixed bed column can be described through the concept of breakthrough curve analysis. The time to reach the breakthrough point and shape of the breakthrough curve are very important characteristics for determining the operation and the dynamic responses of an adsorption column. In our previous batch adsorption study and present optimization using RSM studies, both show that the percentage removal of $\mathrm{Cr}(\mathrm{VI})$ ion is maximum at $\mathrm{pH}$ 2. Thus, the effect of flow rate and bed height was conducted at the solution $\mathrm{pH}$ of 2 .

3.4.1. Effect of Flow Rate. The effect of flow rate for the adsorption $\mathrm{Cr}(\mathrm{VI})$ ions using EAM-CCRCBs was studied at various flow rates of $25 \mathrm{~mL} / \mathrm{min}$ and $50 \mathrm{~mL} / \mathrm{min}$ at bed height of $25 \mathrm{~cm}$, at an inlet concentration $300 \mathrm{mg} / \mathrm{L}$ and is shown in Figure 6. From Figure 6 it is observed that the rapid uptake of metal ion initial stages, later on the rate decreases slowly and finally it reached saturation. For higher flow rate, the rate of reaching the breakthrough time is faster whereas in lower flow rate the rate of reaching the breakthrough time is slower. This may be due to the residence time Distribution of influent concentration to the adsorbent is greater in lower flow rate $[35,36]$.

3.4.2. Effect of Bed Height. The adsorption of $\mathrm{Cr}(\mathrm{VI})$ ions in the packed bed column is largely dependent on the bed height, which is directly proportional to the quantity of EAMCCRCBs in the column. The effect of bed height on breakthrough curve analysis was studied by varying the bed height to $15 \mathrm{~cm}, 20 \mathrm{~cm}$, and $25 \mathrm{~cm}$. The adsorption breakthrough curves were obtained by varying the bed heights at a flow rate of $25 \mathrm{~mL} / \mathrm{min}$ and an inlet $\mathrm{Cr}(\mathrm{VI})$ ion concentration of $300 \mathrm{mg} / \mathrm{L}$. The breakthrough curve is presented in Figure 7. Faster breakthrough curves were observed for a bed height of $15 \mathrm{~cm}$ compared to the bed height of $20 \mathrm{~cm}$ and $25 \mathrm{~cm}$. Higher bed contain more adsorbent; therefore, more binding sites will be available for the $\mathrm{Cr}(\mathrm{VI})$ ions to attach, which makes the rate of reaching of breakthrough time lesser $[35,36]$.

3.4.3. Effect of Initial Metal Ion Concentration. The effects of the two initial $\mathrm{Cr}(\mathrm{VI})$ ions concentrations $(100 \mathrm{mg} / \mathrm{L}$ and $300 \mathrm{mg} / \mathrm{L}$ ) on the adsorption process at a constant flow rate of $25 \mathrm{~mL} / \mathrm{min}$ and fixed bed height of $25 \mathrm{~cm}$ are shown in Figure 
TABLE 7: Optimized process variables value for adsorption of $\mathrm{Cr}(\mathrm{VI})$ ions by EAM-CCRCBs.

\begin{tabular}{lcccccc}
\hline $\begin{array}{l}\text { Adsorbent dosage } \\
(\mathrm{g} / 100 \mathrm{~mL})\end{array}$ & $\begin{array}{l}\text { Initial metal ion } \\
\text { concentration }(\mathrm{mg} / \mathrm{L})\end{array}$ & $\mathrm{pH}$ & \multicolumn{2}{c}{ \% Removal } & \multicolumn{2}{c}{$\begin{array}{c}\text { Adsorption capacity }(\mathrm{mg} / \mathrm{g}) \\
\text { Predicted }\end{array}$} \\
\hline 0.56 & 300 & 2 & 99.80 & 99.60 & 52.70 & Experimental \\
\hline
\end{tabular}

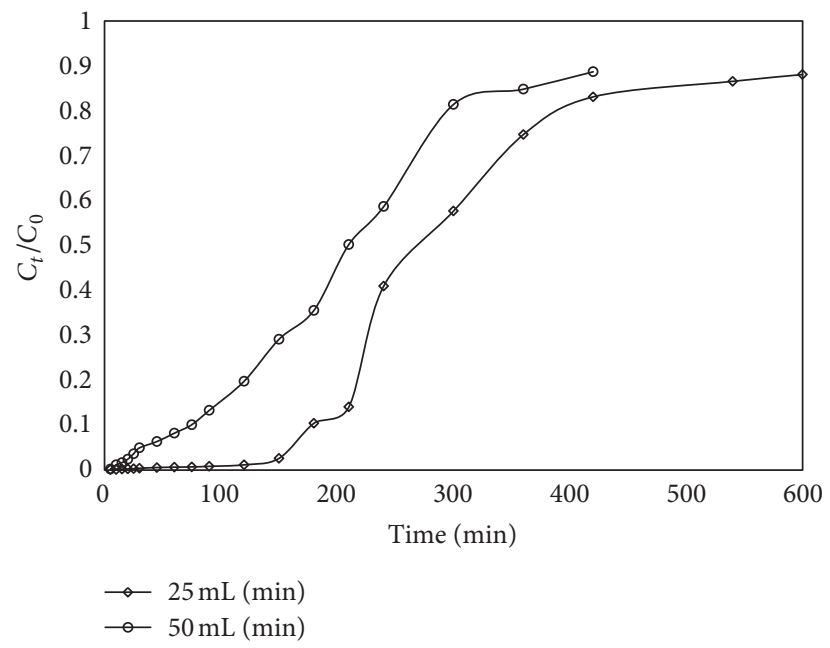

FIGURE 6: Effect of flow rate on breakthrough curve for $\mathrm{Cr}(\mathrm{VI})$ ion adsorption on EAM-CCRCBs $\left(C_{0}=300\right.$, bed height $\left.=25 \mathrm{~cm}\right)$.

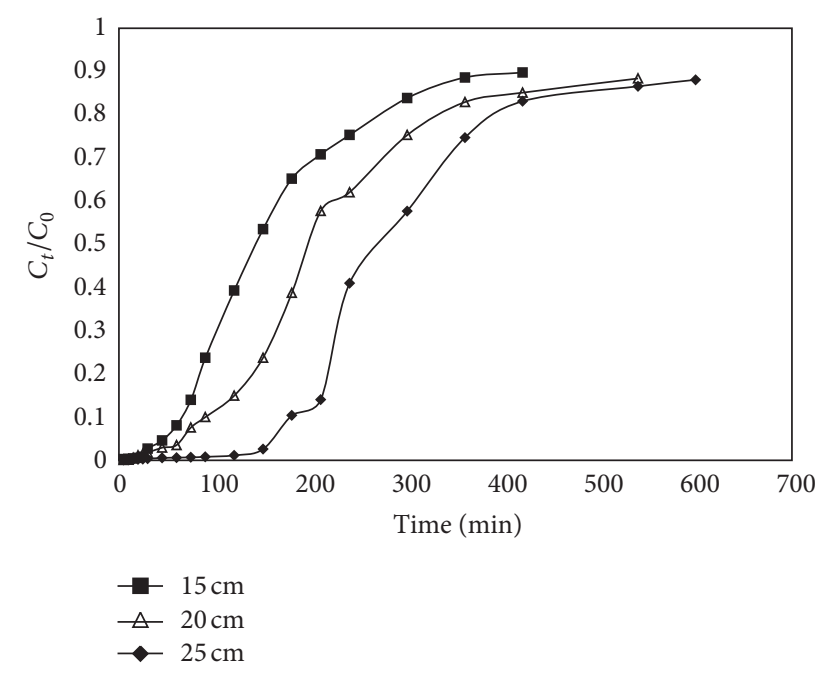

FIGURE 7: Effect of bed height on breakthrough curve for $\mathrm{Cr}(\mathrm{VI})$ ion adsorption on EAM-CCRCBs $\left(C_{0}=300\right.$, flow rate $\left.=25 \mathrm{~mL} / \mathrm{min}\right)$.

8. It can be deduced that, at a lower inlet concentrations, a slower breakthrough curve and the highest treated volume are obtained. The breakthrough point for $100 \mathrm{mg} / \mathrm{L}$ and $300 \mathrm{mg} / \mathrm{L}$ of $\mathrm{Cr}(\mathrm{VI})$ ions inlet concentrations occurred after $360 \mathrm{~min}$ and $150 \mathrm{~min}$ respectively.and $20 \mathrm{~min}$, respectively. The slow transport of $\mathrm{Cr}$ (VI) ions onto EAM-CCRCBs was due to the lower concentration gradient and resulted in a slower breakthrough curve $[35,36]$. Conversely, a higher concentration of $\mathrm{Cr}(\mathrm{VI})$ ions has been shown to lead to a higher driving force for $\mathrm{Cr}(\mathrm{VI})$ ions to overcome the mass transfer resistance in the liquid phase. Consequently, quick

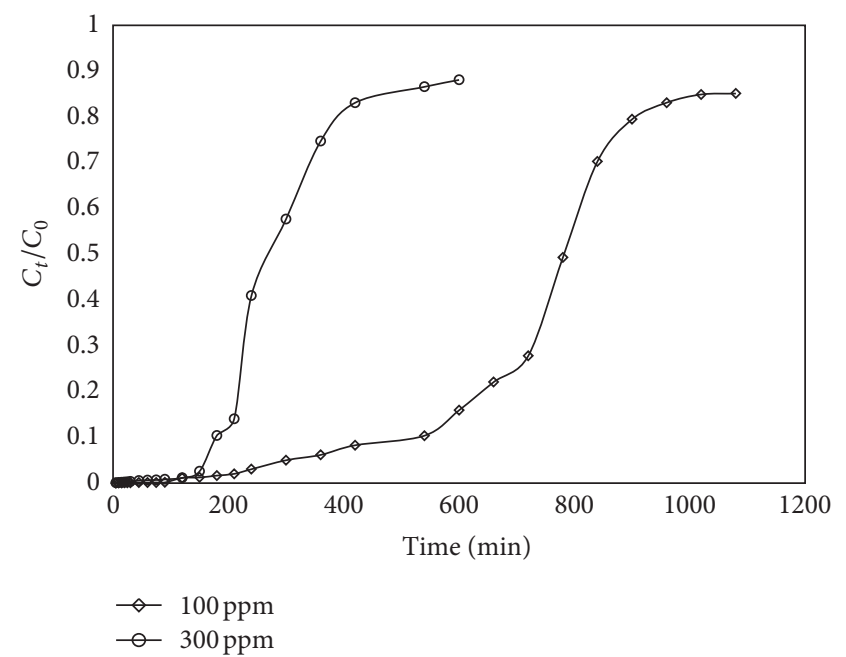

FIGURE 8: Effect of initial concentration on breakthrough curve for $\mathrm{Cr}(\mathrm{VI})$ ion adsorption on EAM-CCRCBs (bed height $=25 \mathrm{~cm}$, flow rate $=25 \mathrm{~mL} / \mathrm{min}$ ).

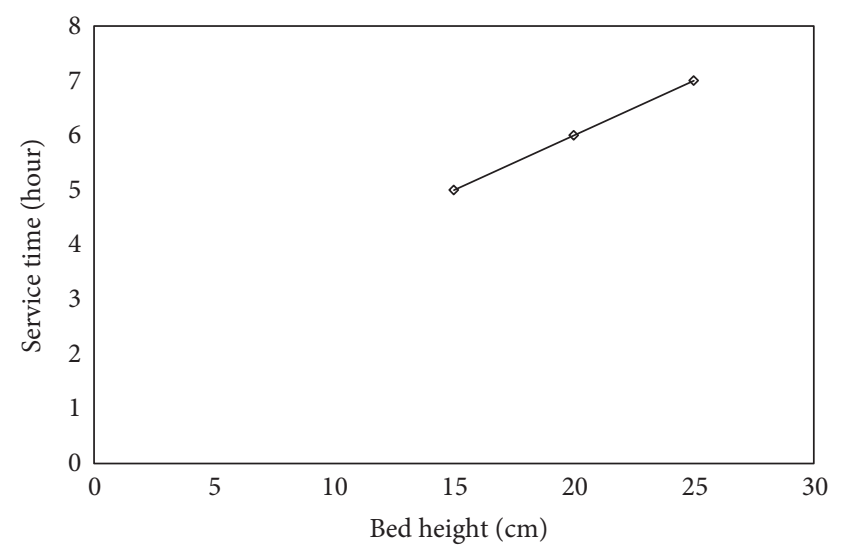

Figure 9: Bed depth service time of column at different bed height $\left(C_{0}=300 \mathrm{mg} / \mathrm{L}\right.$ and flow rate $\left.=25 \mathrm{~mL} / \mathrm{min}\right)$.

saturation of the available binding sites for $\mathrm{Cr}(\mathrm{VI})$ ions has caused the breakthrough time to decrease with the increasing inlet $\mathrm{Cr}(\mathrm{VI})$ ions concentration.

\subsection{Modelling of Experimental Data}

3.5.1. Bed Depth Service Time (BDST). BDST model is used to predict the bed capacity by utilizing the different breakthrough values [37]. The modified version of the equation used in this evaluation is given as follows:

$$
t=\frac{N_{a}}{C_{0} F} Z+\frac{1}{K_{a C_{0}}} \ln \left[\frac{C_{0}}{C_{t}}-1\right],
$$




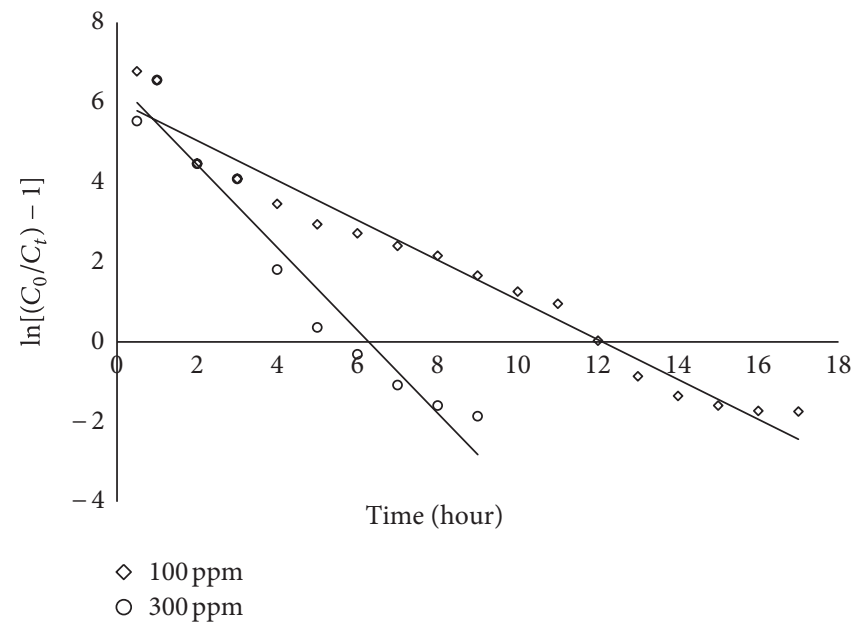

Figure 10: Thomas plot for the adsorption of $\mathrm{Cr}(\mathrm{VI})$ ions on EAM-CCRCBs.

where $t$ is the time (mins), $N_{a}$ is the adsorption capacity $(\mathrm{mg} / \mathrm{L}), \mathrm{C}_{0}$ is the inlet concentration of $\mathrm{Cr}(\mathrm{VI})$ ions $(\mathrm{mg} / \mathrm{L})$, $F$ is the linear velocity of $\mathrm{Cr}(\mathrm{VI})$ ions across the column $(\mathrm{cm} / \mathrm{min}), Z$ is the bed depth $(\mathrm{cm}), K_{a}$ is the rate constant in BDST model $(\mathrm{L} / \mathrm{mg} \cdot \mathrm{min})$, and $C_{t}$ is the effluent concentration of the $\mathrm{Cr}(\mathrm{VI})$ ions $(\mathrm{mg} / \mathrm{L})$. A plot of $t$ versus $Z$ is expected to yield a linear curve in which $N_{0}$ and $K_{a}$ could be evaluated, from the slope and $y$-axis intersection point, respectively.

BDST analysis was done, and the linear plot of this model is given in Figure 9. From Figure 9, the values of $N_{a}$ and $K_{a}$ were determined to be $150 \mathrm{mg} / \mathrm{L}$ and $0.0167 \mathrm{~L} / \mathrm{mg} \cdot \mathrm{min}$, respectively. Besides that, the correlation coefficient value $\left(R^{2}=1.000\right)$ shows that this model is applicable. The constants obtained from this model could be utilized to scaling up the process of this fixed bed column [38].

3.5.2. Thomson Model. Thomas developed a model for adsorption processes in which external and internal diffusion limitations are not present [34]. The linearized form of the Thomas model [36] can be expressed as

$$
\ln \left[\frac{C_{0}}{C_{t}}-1\right]=\frac{k_{\mathrm{Th}} q_{e} W}{\mathrm{Q}}-k_{\mathrm{Th}} C_{0} t
$$

where $k_{\mathrm{Th}}$ is the Thomas rate constant ( $\left.\mathrm{mL} / \mathrm{min} \cdot \mathrm{mg}\right), q_{e}$ is the adsorption capacity of $\mathrm{Cr}(\mathrm{VI})$ ions uptake $(\mathrm{mg} / \mathrm{g}), C_{0}$ is the inlet $\mathrm{Cr}(\mathrm{VI})$ ions concentration $(\mathrm{mg} / \mathrm{L}), C_{t}$ is the effluent $\mathrm{Cr}(\mathrm{VI})$ ions concentration at time $t(\mathrm{mg} / \mathrm{L}), W$ is the mass of adsorbent $(\mathrm{g}), \mathrm{Q}$ is the inlet flow rate $(\mathrm{mL} / \mathrm{min})$, and $t$ is the flow time $(\mathrm{min})$. The value of $C_{0} / C_{t}$ is the ratio of inlet to outlet $\mathrm{Cr}(\mathrm{VI})$ ions concentrations. A linear plot of $\mathrm{ln}$ $\left[\left(C_{o} / C_{t}\right)-1\right]$ against time $(t)$ was drawn to determine the values of $q_{e}$ and $k_{\mathrm{Th}}$ from the interception point and slope of the plot, respectively.

The data obtained from the experiment were fitted to the Thomas model using (7) and are shown in Figure 10 [39]. From Figure 10, it is observed when the inlet $\mathrm{Cr}(\mathrm{VI})$ ions concentration increased from $100 \mathrm{mg} / \mathrm{L}$ to $300 \mathrm{mg} / \mathrm{L}$, the $k_{\mathrm{Th}}$ decreased from 0.004982 to $0.00367 \mathrm{~mL} / \mathrm{min} \cdot \mathrm{mg}$ while the $q_{e}$ increased from to 1730.89 to $2535.07 \mathrm{mg} / \mathrm{g}$. This may be due to the higher driving force of the higher inlet $\mathrm{Cr}(\mathrm{VI})$ ions concentration [40]. The $R^{2}$ values for $100 \mathrm{mg} / \mathrm{L}$ and $300 \mathrm{mg} / \mathrm{L}$ were 0.9632 and 0.9492 , respectively, which shows that Thomas model fits well with the experimental data. Thomas model predicts the monolayer adsorption which also conformed with our earlier batch adsorption studies where the experimental data fits well with Langmuir isotherm.

\section{Conclusion}

RSM is an effective tool for optimizing the process variable. The optimized condition was obtained for the removal of $\mathrm{Cr}(\mathrm{VI})$ ions using EAM-CCRCBs was $300 \mathrm{mg} / \mathrm{L}$ of initial concentration, solution $\mathrm{pH}$ of 2 , and adsorbent dosage of $0.14 \mathrm{~g} / 25 \mathrm{~mL}$. The breakthrough curve analysis from continuous adsorption studies reveals that the slower breakthrough time reached for lesser initial concentration, slower flow rate, and higher bed height. Bed Height service model and Thomson model were well fitted with experimental data. Thomson model reveals the monolayer adsorption which also conformed with our earlier batch adsorption studies where the experimental data fitted well with Langmuir adsorption isotherm.

\section{Acknowledgment}

The financial support given by the National Institute of Technology, Tiruchirappalli-15 for this research work is gratefully acknowledged.

\section{References}

[1] J. Rivera-Utrilla, I. Bautista-Toledo, M. A. Ferro-García, and C. Moreno-Castilla, "Bioadsorption of $\mathrm{Pb}(\mathrm{II}), \mathrm{Cd}(\mathrm{II})$, and $\mathrm{Cr}(\mathrm{VI})$ on activated carbon from aqueous solutions," Carbon, vol. 41, no. 2, pp. 323-330, 2003.

[2] U. K. Garg, M. P. Kaur, D. Sud, and V. K. Garg, "Removal of hexavalent chromium from aqueous solution by adsorption on 
treated sugarcane bagasse using response surface methodological approach," Desalination, vol. 249, no. 2, pp. 475-479, 2009.

[3] M. Owlad, M. K. Aroua, W. A. W. Daud, and S. Baroutian, "Removal of hexavalent chromium-contaminated water and wastewater: a review," Water, Air, and Soil Pollution, vol. 200, no. 1-4, pp. 59-77, 2009.

[4] EPA, "Environmental pollution control alternatives," EPA/625/ 5-90/25, EPA/625/4-89/023 Environmental Protection Agency, Cincinaati, Ohio, USA, 1990.

[5] L. Monser and N. Adhoum, "Modified activated carbon for the removal of copper, zinc, chromium and cyanide from wastewater," Separation and Purification Technology, vol. 26, no. 2-3, pp. 137-146, 2002.

[6] A. A. Attia, S. A. Khedr, and S. A. Elkholy, "Adsorption of chromium ion (VI) by acid activated carbon," Brazilian Journal of Chemical Engineering, vol. 27, no. 1, pp. 183-193, 2010.

[7] S. Chatterjee, D. S. Lee, M. W. Lee, and S. H. Woo, "Congo red adsorption from aqueous solutions by using chitosan hydrogel beads impregnated with nonionic or anionic surfactant," Bioresource Technology, vol. 100, no. 17, pp. 3862-3868, 2009.

[8] E. Thirunavukkarasu and K. Palanivelu, "Biosorption of Cr(VI) from plating effluent using marine algal mass," Indian Journal of Biotechnology, vol. 6, no. 3, pp. 359-364, 2007.

[9] M. Yi冈ito囚lu and M. Arslan, "Adsorption of hexavalent chromium from aqueous solutions using 4-vinyl pyridine grafted poly(ethylene terephthalate) fibers," Polymer Bulletin, vol. 55, no. 4, pp. 259-268, 2005.

[10] E. I. El-Shafey, "Behaviour of reduction-sorption of chromium (VI) from an aqueous solution on a modified sorbent from rice husk," Water, Air, and Soil Pollution, vol. 163, no. 1-4, pp. 81-102, 2005.

[11] H. Jaman, D. Chakraborty, and P. Saha, "A study of the thermodynamics and kinetics of copper adsorption using chemically modified rice husk," Clean, vol. 37, no. 9, pp. 704-711, 2009.

[12] N. Yalçin and V. Sevinç, "Studies of the surface area and porosity of activated carbons prepared from rice husks," Carbon, vol. 38, no. 14, pp. 1943-1945, 2000.

[13] Y. Guo, S. Yang, K. Yu, J. Zhao, Z. Wang, and H. Xu, “The preparation and mechanism studies of rice husk based porous carbon," Materials Chemistry and Physics, vol. 74, no. 3, pp. 320-323, 2002.

[14] Y. Guo, K. Yu, Z. Wang, and H. Xu, "Effects of activation conditions on preparation of porous carbon from rice husk," Carbon, vol. 41, no. 8, pp. 1645-1647, 2000.

[15] S. M. Nomanbhay and K. Palanisamy, "Removal of heavy metal from industrial wastewater using chitosan coated oil palm shell charcoal," Electronic Journal of Biotechnology, vol. 8, no. 1, pp. 43-53, 2005.

[16] S. Maghsoodloo, B. Noroozi, A. K. Haghi, and G. A. Sorial, "Consequence of chitosan treating on the adsorption of humic acid by granular activated carbon," Journal of Hazardous Materials, vol. 191, no. 1-3, pp. 380-387, 2011.

[17] M. Hasan, A. L. Ahmad, and B. H. Hameed, "Adsorption of reactive dye onto cross-linked chitosan/oil palm ash composite beads," Chemical Engineering Journal, vol. 136, no. 2-3, pp. 164-172, 2008.

[18] M. Y. Chang and R. S. Juang, "Adsorption of tannic acid, humic acid, and dyes from water using the composite of chitosan and activated clay," Journal of Colloid and Interface Science, vol. 278, no. 1, pp. 18-25, 2004.
[19] E. Repo, J. K. Warchol, T. A. Kurniawan, and M. E. T. Sillanpää, "Adsorption of $\mathrm{Co}(\mathrm{II})$ and $\mathrm{Ni}$ (II) by EDTA- and/or DTPA-modified chitosan: kinetic and equilibrium modeling," Chemical Engineering Journal, vol. 161, no. 1-2, pp. 73-82, 2010.

[20] C. Septhum, S. Rattanaphani, J. B. Bremner, and V. Rattanaphani, "An adsorption study of $\mathrm{Al}(\mathrm{III})$ ions onto chitosan," Journal of Hazardous Materials, vol. 148, no. 1-2, pp. 185-191, 2007.

[21] G. Crini and P. M. Badot, "Application of chitosan, a natural aminopolysaccharide, for dye removal from aqueous solutions by adsorption processes using batch studies: a review of recent literature," Progress in Polymer Science, vol. 33, no. 4, pp. 399-447, 2008.

[22] C. Zhang and Z. Jia, "Preparation of porous chitosan microsphere adsorbent and research on its absorption ability for $\mathrm{Cu}^{2+}$ and $\mathrm{Zn}^{2+}$, International Journal of Chemistry, vol. 2, no. 1, pp. 113-119, 2010.

[23] L. Zhou, Y. Wang, Z. Liu, and Q. Huang, "Characteristics of equilibrium, kinetics studies for adsorption of $\mathrm{Hg}(\mathrm{II}), \mathrm{Cu}(\mathrm{II})$, and $\mathrm{Ni}(\mathrm{II})$ ions by thiourea-modified magnetic chitosan microspheres," Journal of Hazardous Materials, vol. 161, no. 2-3, pp. 995-1002, 2009.

[24] K. P. Singha, S. Gupta, A. K. Singh, and S. Sinha, "Optimizing adsorption of crystal violet dye from water by magnetic nanocomposite using response surface modeling approach," Journal of Hazardous Materials, vol. 186, no. 2-3, pp. 1462-1473, 2011.

[25] W. S. W. Ngah, M. A. Hanafiah, and S. S. Yong, "Adsorption of humic acid from aqueous solutions on crosslinked chitosanepichlorohydrin beads: kinetics and isotherm studies," Colloids and Surfaces B, vol. 65, no. 1, pp. 18-24, 2008.

[26] Y. Tao, L. Ye, J. Pan, Y. Wang, and B. Tang, "Removal of Pb(II) from aqueous solution on chitosan $/ \mathrm{TiO}_{2}$ hybrid film," Journal of Hazardous Materials, vol. 161, no. 2-3, pp. 718-722, 2009.

[27] M. Jain, V. K. Garg, and K. Kadirvelu, "Investigation of $\mathrm{Cr}(\mathrm{VI})$ adsorption onto chemically treated Helianthus annuus: optimization using response surface methodology," Bioresource Technology, vol. 102, no. 2, pp. 600-605, 2011.

[28] S. Sugashini and K. M. Meera S. Begum, "Studies on the performance of ethylamine modified chitosan carbonized rice husk composite beads (EAM-CCRCBs) for adsorption of metal ion," Bioremediation. In press.

[29] M. Sindhu, K. M. Meera S. Begum, and S. Sugashini, "A comparative study of surface modification in carbonized rice husk by acid treatment," Desalination and Water Treatment, vol. 45 , pp. $170-176,2012$.

[30] M. T. Tanyildizi, "Modeling of adsorption isotherms and kinetics of reactive dye from aqueous solution by peanut hull," Chemical Engineering Journal, vol. 168, no. 3, pp. 1234-1240, 2011.

[31] A. A. Ahmad, B. H. Hameed, and A. L. Ahmad, "Removal of disperse dye from aqueous solution using waste-derived activated carbon: optimization study," Journal of Hazardous Materials, vol. 170, no. 2-3, pp. 612-619, 2009.

[32] J. N. Sahu, J. Acharya, and B. C. Meikap, "Response surface modeling and optimization of chromium(VI) removal from aqueous solution using Tamarind wood activated carbon in batch process," Journal of Hazardous Materials, vol. 172, no. 2-3, pp. 818-825, 2009.

[33] H. Kalavathy, I. Regupathi, M. G. Pillai, and L. R. Miranda, "Modelling, analysis and optimization of adsorption parameters for $\mathrm{H}_{3} \mathrm{PO}_{4}$ activated rubber wood sawdust using response 
surface methodology (RSM)," Colloids and Surfaces B, vol. 70, no. 1, pp. 35-45, 2009.

[34] J. T. Nwabanne, A. C. Okoye, and B. T. Lebele-Alawa, "Packed bed column studies for the removal of Lead (II) using oil palm empty fruit bunch," European Journal of Scientific Research, vol. 63, pp. 296-305, 2011.

[35] S. Sugashini and K. M. Meera Sheriffa Begum, "Optimization using central composite design (CCD) for the biosorption of $\mathrm{Cr}$ (VI) ions by cross linked chitosan carbonized rice husk (CCACR)," Clean Technologies and Environmental Policy, In press.

[36] R. Han, Y. Wang, W. Yu, W. Zou, J. Shi, and H. Liu, "Biosorption of methylene blue from aqueous solution by rice husk in a fixedbed column," Journal of Hazardous Materials, vol. 141, no. 3, pp. 713-718, 2007.

[37] R. Han, Y. Wang, X. Zhao et al., "Adsorption of methylene blue by phoenix tree leaf powder in a fixed-bed column: experiments and prediction of breakthrough curves," Desalination, vol. 245, no. 1-3, pp. 284-297, 2009.

[38] H. C. Thomas, "Heterogeneous ion exchange in a flowing system," Journal of the American Chemical Society, vol. 66, no. 10, pp. 1664-1666, 1944.

[39] D. Martínez, E. Pocurull, R. M. Marcé, F. Borrull, and M. Calull, "Separation of eleven priority phenols by capillary zone electrophoresis with ultraviolet detection," Journal of Chromatography A, vol. 734, no. 2, pp. 367-373, 1996.

[40] T. V. N. Padmesh, K. Vijayaraghavan, G. Sekaran, and M. Velan, "Batch and column studies on biosorption of acid dyes on fresh water macro alga Azolla filiculoides," Journal of Hazardous Materials, vol. 125, no. 1-3, pp. 121-129, 2005. 

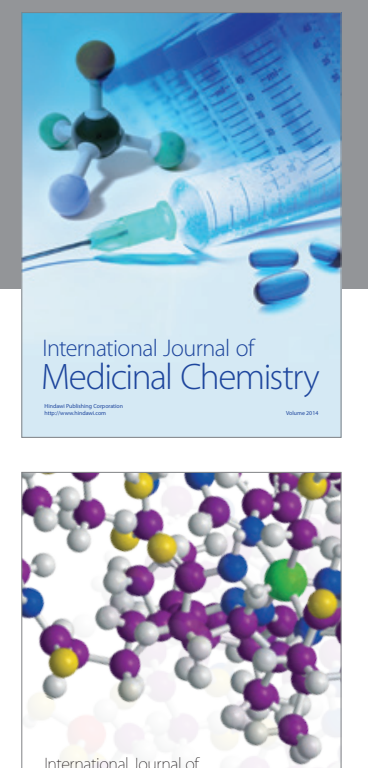

\section{Carbohydrate} Chemistry

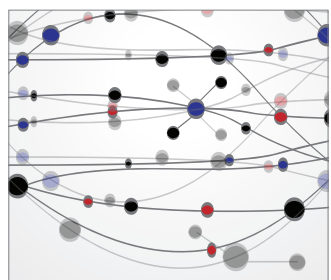

The Scientific World Journal
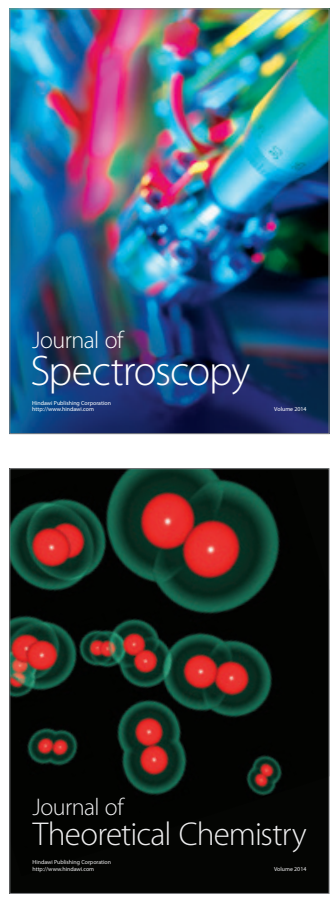
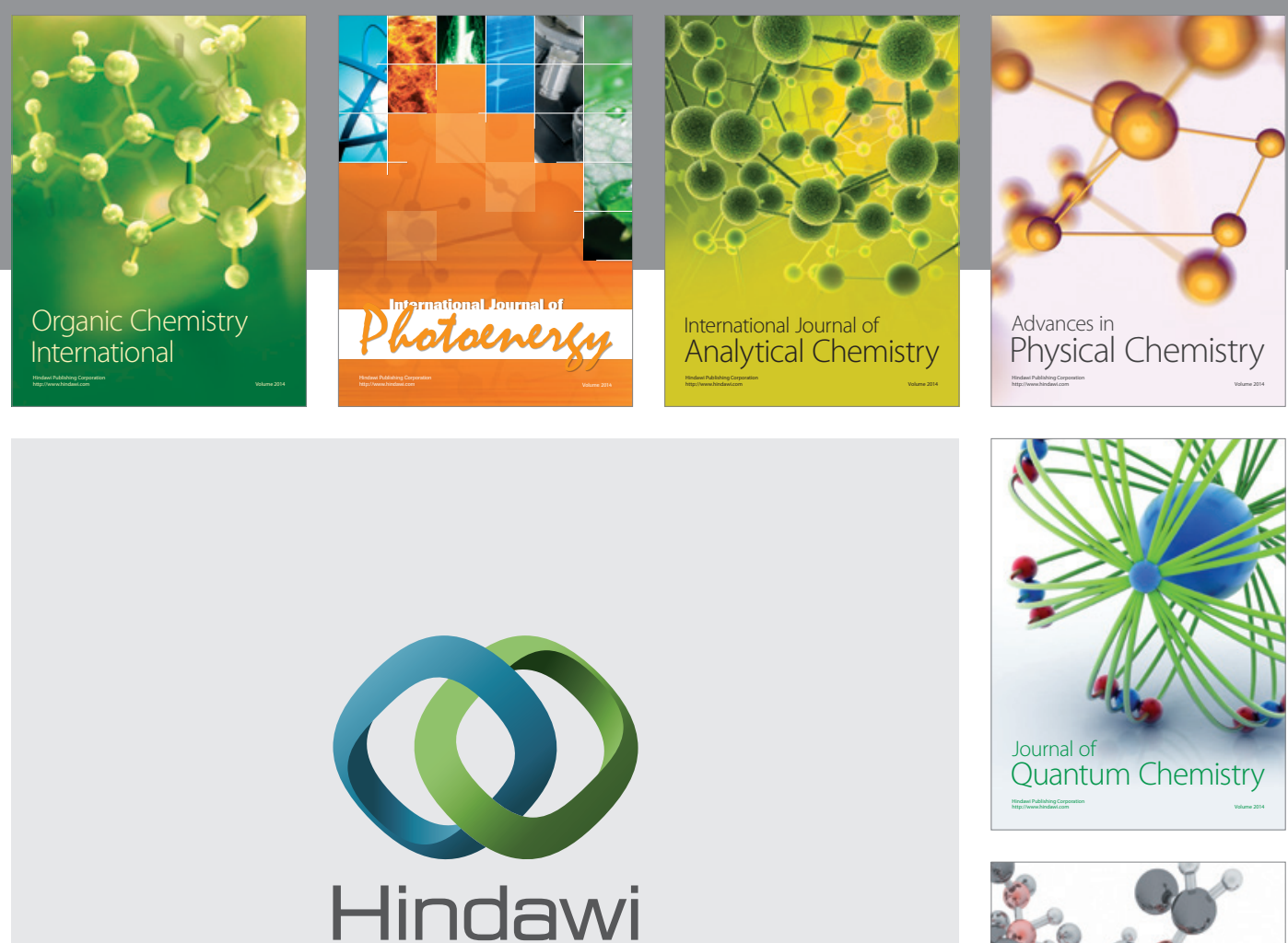

Submit your manuscripts at

http://www.hindawi.com

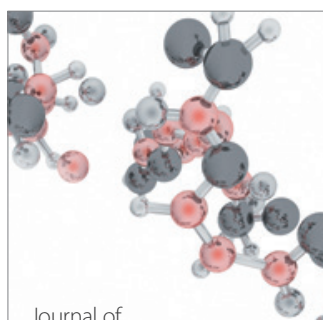

Analytical Methods

in Chemistry

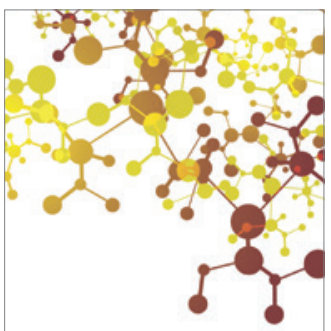

Journal of

Applied Chemistry

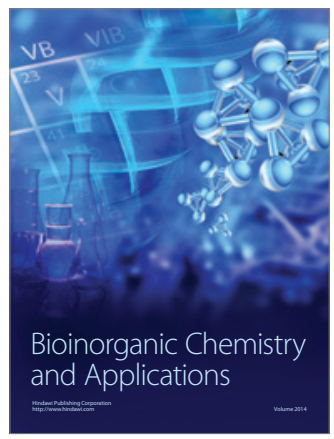

Inorganic Chemistry
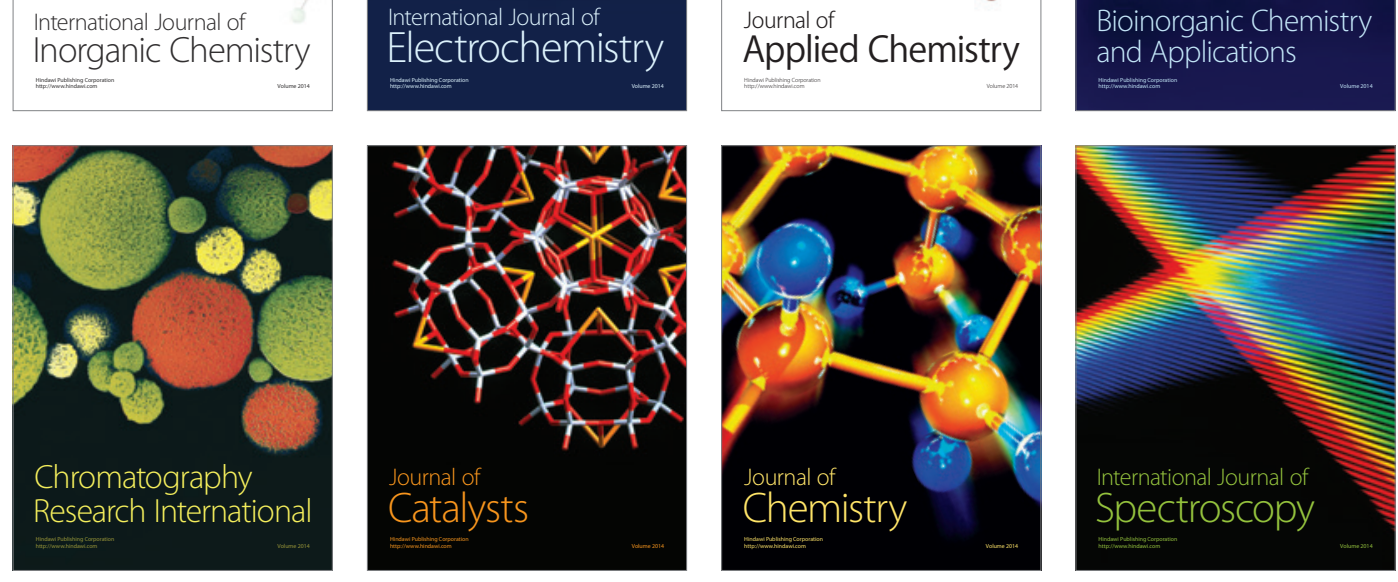